\title{
Complications and limitations of injection sclerotherapy in portal hypertension
}

The pioneering work of Whipple in $1945^{\prime}$ began an era of portosystemic shunt surgery for portal hypertension which remained the primary form of treatment for nearly 30 years even though the consequences of portal diversion such as liver atrophy and encephalopathy were soon recognised. ${ }^{2}$ Repeated trials in patients with bleeding varices confirmed that the complications of medical management were related to recurrent bleeding whereas surgical treatment was followed by liver failure and encephalopathy. Refinements of surgical technique eventually culminated in the selective shunt procedures developed by Warren $e t a l^{3}$ which were designed to decompress the gastro-oesophageal varices while preserving portal blood flow and liver function.

Endoscopic sclerotherapy as an alternative form of treatment for bleeding varices was first reported in $1939^{4}$ in a young patient with extrahepatic portal vein occlusion and was eventually popularised as an alternative to surgery by the work of Johnston and Rodgers. ${ }^{5}$ A number of controlled trials rapidly established the effectiveness of this treatment and the value of sclerotherapy in the initial management of bleeding varices, particularly in the cirrhotic patient, is now generally recognised..$^{610}$ The variety of complications that may be associated with sclerotherapy is less well known, and the role of surgery in the management of recurrent bleeding and other sequelae is not always appreciated.

\section{Uncontrolled oesophageal bleeding}

Randomised controlled trials in patients with chronic liver disease have shown that endoscopic sclerotherapy reduces the risk of rebleeding from oesophageal varices ${ }^{811}{ }^{12}$ and may prolong survival. Rebleeding during a course of endoscopic sclerotherapy treatment occurs in $23 \%-55 \%$ of patients ${ }^{13}$ and remains a significant cause of death in the cirrhotic patient. The reported figures for failure of sclerotherapy vary widely from $5 \%$ to $60 \%,{ }^{8101415}$ but this variation can be partly explained by the lack of a universal definition of 'failure of treatment'. Westaby ${ }^{16}$ defined a failure of sclerotherapy as an inability to control an episode of variceal bleeding rather than episodes of recurrent bleeding easily controlled by further injections. Using this definition at King's College Hospital, surgical intervention was necessary in 12 of 252 children $(4 \cdot 4 \%)$ and 25 of 540 of adults $(4 \cdot 6 \%)$ with bleeding oesophageal varices treated by injection sclerotherapy over a five year period. A similar failure rate for sclerotherapy of $6 \%$ was reported by Jenkins and Shields ${ }^{17}$ in patients presenting with their first episode of variceal haemmorhage. There was a recurrent bleeding rate of $42 \%$ in this series, only $13 \%$ of whom were uncontrolled by conservative treatment. The failures usually occurred in patients with poor liver function.

The options available for the surgical treatment of variceal haemorrhage during or after sclerotherapy now include hepatic transplantation as well as devascularisation or portosystemic shunting. Control of bleeding with a SengstakenBlakemore tube followed by emergency transplantation has been suggested for patients with poor hepatic reserve, ${ }^{18}$ and Iwatsuki et $a l^{19}$ have proposed that transplantation is the best option for most patients with advanced liver disease and recurrent bleeding. This ideal management, however, cannot be offered to most patients, who will either not be on a transplant programme or who may be too ill for such a radical procedure. Other forms of surgery are, therefore, still necessary for the many patients who suffer uncontrollable or repeated haemorrhage after sclerotherapy. It is now clear that an emergency portosystemic shunt or a devascularisation procedure does not necessarily prejudice the subsequent performance of liver transplantation..$^{20}$

Emergency portosystemic shunting is still recommended by some centres as the most effective therapy for bleeding ${ }^{21-24}$ while others prefer staple gun transection of the oesophagus which is the safer technique for the less experienced surgeon. ${ }^{25}$ Emergency oesophageal transection which includes devascularisation of the lower oesophagus and the upper two thirds of the stomach is associated with mortality rates of up to $30 \%,{ }^{26}$ which are similar to mortality figures reported after emergency shunting. The King's College Hospital series showed mortality rates of $10 \%$ for portosystemic shunt therapy and $40 \%$ for emergency devascularisation procedures, but these treatment groups were selected on the basis of portal anatomy and liver function status and were not therefore comparable.

Millikan et $a l^{27}$ made an interesting comparison of biochemical and physiological data in 24 patients who had undergone transplantation and a group of patients treated with shunt surgery and sclerotherapy. The authors concluded that patients with good liver function usually progress well after appropriate shunt surgery whereas those with advanced disease will need transplantation. They also proposed that the aetiology of the portal hypertension might influence the type of surgery offered for recurrent bleeding from failed sclerotherapy.

\section{Gastric varices}

Gastric varices are not uncommon in cirrhotic patients with portal hypertension. ${ }^{28}$ Most are a direct continuation of oesophageal varices and may respond to injection sclerotherapy from reflux of sclerosant below the cardia. Sarin et $a l^{29}$ found that gastric varices disappeared in $28 \%$ of patients with endoscopic obliteration of oesophageal varices while Terblanche $e t a l^{30}$ reported the disappearance of all gastric varices after successful sclerotherapy. Approximately $5 \%$ of patients have a risk of bleeding from gastric varices after successful obliteration of their oesophageal veins. ${ }^{31} 32$

Fundal varices originate from the short gastric and epiploic veins in about $12 \%$ of patients ${ }^{33}$ and occasionally follow an isolated splenic vein thrombosis. They are usually inaccessible to endoscopic injection sclerotherapy, particularly when accompanied by acute bleeding, although Sarin et $^{2} l^{29}$ did control haemorrhage in 6 of 8 patients. Gastric varices are particularly difficult to diagnose during active bleeding. Under-running of the bleeding varix with or without devascularisation or portosystemic shunting are possible surgical options. 


\section{Ectopic varices}

Ectopic varices, defined as varices arising in sites other than the oesophagus or cardia of the stomach, may develop spontaneously following endoscopic obliteration of oesophageal varices or occur as a result of surgery and subsequent adhesion formation. The prevalence of bleeding from this type of varix has been reported in $1.4 \%$ to $5 \%$ of patients with intrahepatic portal hypertension and in $27 \%$ to $40 \%$ of patients with extrahepatic portal hypertension. ${ }^{34}$

Duodenal varices account for one third of all ectopic variceal bleeding and usually occurs in adults. ${ }^{35}$ However, they are well recognised in children with extrahepatic portal hypertension and almost half of these patients have a history of previous surgery. Successful treatment of duodenal varices has been reported with injection sclerotherapy, but surgical ligation or portosystemic decompression is usually required.

Jejunal and ileal varices account for approximately one third of bleeding ectopic varices. ${ }^{34}$ These patients usually have a history of previous abdominal or pelvic surgery and collaterals develop via adhesions between the gastrointestinal tract and the abdominal wall. Patients bleed from large submucosal veins within the small bowel and although surgical excision of the affected segment may provide long term relief, recurrent bleeding can occur as further adhesions are formed. A portosystemic shunt is the treatment of choice if liver function is satisfactory.

Bleeding from colonic varices is a rare clinical problem but may account for up to $25 \%$ of bleeding ectopic varices, particularly in cirrhotic patients. ${ }^{34}$ Approximately half of the varices are localised to the distal colon and rectum, ${ }^{36}$ and $20 \%$ of patients have had previous surgical operations. ${ }^{34}$ The varices may be seen on barium enema or at colonoscopy and aortoportography is diagnostic. The mortality after partial or total colectomy in adult patients with cirrhosis is more than $60 \%^{34}$ and portosystemic shunting or transplantation, depending on the status of the liver disease, is preferable.

Anorectal varices represent collateral formation between the superior rectal vein which drains the submucosa of the lower rectum and upper part of the anal canal and the systemic venous drainage at the anus. In a prospective study of 100 cirrhotic patients, Hosking et $a l^{37}$ found anorectal varices in $44 \%$ and haemorrhoids in $63 \%$ of patients. There was no clear relationship between the severity of portal hypertension and the prevalence of haemorrhoids, which have previously been shown to have no direct communication with the portal vein. ${ }^{38}$ Anorectal complications of portal hypertension may occur early in life and in a recent study of children $4 \cdot 7 \%$ presenting with bleeding oesophageal varices had symptomatic rectal varices or haemorrhoids.

The treatment of bleeding anorectal varices includes injection sclerotherapy, banding, cryosurgery, underrunning of varices, haemorrhoidectomy, embolisation, and portosystemic shunt. ${ }^{39}{ }^{40}$ Injection sclerotherapy is usually satisfactory for treating true haemorrhoids, but direct suture or banding are probably the more effective treatments for anorectal varices. ${ }^{40+1}$

The formation of varices at the mucocutaneous junctions of small or large bowel stomas in patients with portal hypertension can be a source of massive or recurrent haemorrhage. Haemorrhage can be controlled by intraperitoneal closure of a temporary stoma, ${ }^{42}$ but the management of a permanent stoma is more difficult. Resuture of the stoma edge will be followed inevitably by recurrent bleeding and we have found that the therapeutic options are either a portosystemic shunt, if liver function is well preserved, or transplantation.

Spontaneous rupture of intraperitoneal varices is a rare complication in adults. The typical presentation is one of sudden onset of acute abdominal pain, hypotension, and increasing abdominal girth in a patient with cirrhosis. Urgent surgical treatment by direct suture ligation is the treatment of choice, but the prognosis for most patients is extremely poor. ${ }^{+3}$

Adhesion related varices should be suspected in patients with recurrent melaena with a history of previous surgery and in whom upper intestinal endoscopy is unhelpful. Varices may form along adhesions between the abdominal wall and the gastrointestinal tract, particularly the small bowel..$^{+1+5}$ Labelled red blood cells and selective visceral angiography have been recommended to establish the diagnosis. ${ }^{+6}$ Localised resection of the affected segment has been performed, but adhesion varices tend to recur and are best treated by portosystemic shunting.

Massive splenic enlargement often accompanied by discomfort or pain in the left side of the abdomen is another uncommon but difficult problem in patients with unrelieved portal hypertension who have undergone variceal sclerosis. Abdominal symptoms or haematological changes of hypersplenism can be severe enough to warrant surgery.

\section{Specific complications associated with endoscopic sclerotherapy}

\section{LOCAL COMPLICATIONS}

The commonest complaints after injection sclerotherapy are of fever, retrosternal discomfort, and transient dysphagia which resolve within $24-48$ hours. ${ }^{478}$ The inflammatory reaction underlying this local complication occasionally becomes more widespread and causes mediastinitis, pericarditis, and even cardiac tamponade. ${ }^{99}$ Pleural effusions are found in up to half these patients, ${ }^{50}$ although most are small and without clinical significance. Patients developing these complications have usually had large volume injections of sclerosant and postsclerotherapy chest pain. Other rare local complications of injection sclerotherapy include perforation of the thoracic duct with the development of a massive chylothorax, ${ }^{51}$ oesophageal perforation, and bronchooesophageal fistula from delayed oesophageal necrosis. ${ }^{52}$

Oesophageal ulceration is common, usually asymptomatic, and more likely to follow large volume or frequent injections of sclerosant. ${ }^{53}$ Bleeding from these ulcers is often related to portal hypertension and may be controlled with an infusion of somatostatin, but occasionally it is related to arterial damage which will only respond to prompt surgical intervention. Oesophageal strictures are probably caused by a combination of chemical oesophagitis, ulceration, and acid reflux. They were found in $16 \%$ of 98 children who had completed a course of sclerotherapy, ${ }^{54}$ all of whom responded to simple dilatation. Three patients continued to complain of intermittent dysphagia suggestive of a motility disturbance and these changes are probably permanent. ${ }^{47}$ There is no clear correlation between the number of injections and the degree of abnormality recorded. Minor falls in the mean resting pressure of the lower oesophageal sphincter and increased gastro-oesophageal reflux have been noted, ${ }^{55}$ but the most striking abnormality has been the incoordinated passage of oesophageal pressure waves. ${ }^{+7}$

Severe respiratory complications have also been reported after sclerotherapy including respiratory distress syndrome, pneumonia and atelectasis.

SYSTEMIC COMPLICATIONS OF INJECTION SCLEROTHERAPY More widespread complications of sclerotherapy have been described and may be commoner than previously suspected. ${ }^{56}$ Portal vein thrombosis may occur. Barsoum et al ${ }^{57}$ reported a post mortem finding after sclerotherapy of portal vein thrombus extending into the left gastric vein and the submucosal plexus of the oesophagus. Another post mortem 
study of three patients showed portal vein thrombosis with fresh thrombus extending from recently injected varices. ${ }^{58}$ Intimal thickening, medial fibrosis, and microthrombus formation in the splenic vein have also been observed at the time of portosystemic shunt surgery in patients treated previously by injection sclerotherapy. ${ }^{5659}$ However spontaneous portal vein thrombus may occur in portal hyperten$\operatorname{sion}^{60}$ and the infusion of vasopressin may also play a part.

Case reports of rare complications of sclerotherapy include spinal cord paralysis after injection of sclerosant in the midoesophagus, ${ }^{61}$ brain abscess,${ }^{62}$ digital gangrene,${ }^{63}$ and acute renal failure ${ }^{6 t}$ Mild and transient disseminated intravascular coagulopathy has been described, ${ }^{6566}$ and transient bacteraemia occurs in 5-8\% of patients during upper gastrointestinal endoscopy. ${ }^{67}$ Staphylococcus aureus and alpha haemolytic streptococci were the most commonly identified organisms and were usually isolated from the biopsy channel of the endoscope and it seems likely that needle tip contamination is the chief culprit. Antibiotic prophylaxis is imperative for immunosuppressed patients or for those with valvular heart disease or prosthetic graft material. Anaphylactic shock has also been recorded after injection sclerotherapy using ethanolamine oleate. ${ }^{68}$

\section{Summary}

Injection sclerotherapy is now the accepted first line treatment for bleeding oesophageal varices, although it is associated with an impressive list of rare complications. The main problem concerns the strategy for uncontrollable or recurrent bleeding. Patients with uncontrolled bleeding may be referred for surgery after considerable blood loss and are then extremely difficult to assess. The effects of blood loss on liver function can lead to an unduly pessimistic assessment of liver status.

An effective choice of emergency surgical procedure may require considerable surgical expertise. Oesophageal transection and devascularisation are satisfactory for many patients with oesophageal varices secondary to cirrhosis and should nearly always control bleeding. Difficulties arise in patients who are grossly obese and in those who have undergone extensive surgery in the upper abdomen. Problems may also be encountered in those treated by repeated sclerotherapy, which may have caused severe inflammatory change and thickening around the lower oesophagus and upper stomach. We believe that an emergency mesocaval shunt using either a vein graft or a synthetic material such as polytetrafluoroethylene is the procedure of choice for this difficult group of very sick patients. The surgical exposure is satisfactory and not unduly prolonged in even the largest patients and the technique does not interfere with any subsequent transplant operation.

There is a greater choice in the management of the patient with less urgent bleeding from recurrent varices after sclerotherapy. Repeat sclerotherapy may be effective for small oesophageal varices while liver transplantation may be indicated in the patient with deteriorating liver function. A selective distal splenorenal shunt should be considered for patients with intact splenic and left renal veins and a mesocaval vein graft for the remainder.

We would therefore suggest that surgery should still be considered for the management of portal hypertension, particularly in the following circumstances:

(1) Uncontrollable bleeding during the initial course of sclerotherapy;

(2) Life threatening haemorrhage from recurrent varices;

(3) Bleeding from ectopic varices not accessible to sclerotherapy;

(4) Uncontrollable bleeding from oesophageal ulceration secondary to injection sclerotherapy;
(5) Severe, symptomatic hypersplenism;

(6) For patients who live in communities remote from blood transfusion facilities and adequate medical care.

The management of the complications of portal hypertension continues to pose problems. We believe that the best results should come from a combined management approach using injection sclerotherapy as primary treatment and surgery for complications and for haemorrhage from unusual anatomical sites.

NIGEL D HEATON EDWARD R HOWARD

Department of Surgery,

King's College Hospital,

Denmark Hill,

London SE $59 R S$.

Correspondence to: Mr E R Howard

1 Whipple AO. The problem of portal hypertension in relation to hepatosplenopathies. Ann Surg 1945; 122: 449-75.

2 McDermott MV, Adams RD. Episodic stupor associated with an Eck fistula in the human with particular reference to the metabolism of ammonia. $\mathcal{F}$ Clin Invest 1954; 33: 1-9.

3 Warren WD, Zeppa R, Fomon JJ. Selective transsplenic decompression of esophageal varices by distal splenorenal shunt. Ann Surg 1967; 166: 437-55.

4 Craaford C, Frenckner P. New surgical treatment of varicose veins of the oesophagus. Acta Otolargyngol 1939; 27: 422-9.

5 Johnston GW, Rodgers HW. A review of 15 years experience in the use of sclerotherapy in the control of acute haemorrhage from oesophageal varices. Brf Surg 1973; 60: 797-800.

6 Barsoum MS, Boulous FI, El-Robby A, et al. Tamponade and injection sclerotherapy in the management of bleeding oesophageal varices. BrF Surg 1982; 69: 76-8

7 Korula J, Balart LA, Radvan G, et al. A prospective, randomized controlled trial of chronic esophageal variceal sclerotherapy. Hepatology 1984;5:584-9.

The Copenhagen esophageal varices sclerotherapy project. Sclerotherapy after lst variceal haemorrhage in cirrhosis: a randomized multi-centre trial. NEnglf Med 1984; 311: 1594-600.

9 Westaby D, MacDougall BRD, Williams R. Improved survival following injection sclerotherapy for oesophageal varices: final analysis of a controlled trial. Hepatology 1985; 5: 827-30.

10 Paquet KJ, Feussner H. Endoscopic sclerosis and esophageal balloon tamponade in acute hemorrhage from esophagogastric varices: a prospective controlled randomized trial. Hepatology 1985; 5: 580-3.

11 Terblanche J, Bornman PC, Kahn D, et al. Failure of repeated injection sclerotherapy to improve long-term survival after oesophageal variceal bleeding. Lancet 1983; ii: 1328-32.

12 Yassin YM, Sharif SM. Randomized controlled trial of injection sclerotherapy for bleeding oesophageal varices. An interim report. Br $\mathcal{F}$ Surg 1983; 70: for 2 .

13 MacDougall BRD, Westaby D, Theodossi A, Dawson JL, Williams R. Increased long-term survival in variceal haemorrhage using injection scleroIncreased long-term survival in variceal haemorrhage using

14 Larson AW, Cohen H, Zweiban B, et al. Acute esophageal variceal sclerotherapy: results of a prospective randomized controlled trial. $\mathcal{F} A M A 1986$ 255: 497-500.

15 Soderland C, Ihre T. Endoscopic sclerotherapy v. conservative management of bleeding oesophageal varices. Acta Chir Scand 1985; 151: 449-56.

16 Westaby D, Williams R. Status of sclerotherapy for variceal bleeding. Am $\mathcal{f}$ Surg 1990; 160: $32-6$.

17 Jenkins SA, Shields R. Variceal haemorrhage after failed injection sclerotherapy: the role of emergency oesophageal transection. Brf Surg 1989; 76: 49-51.

18 Pillay P, Starzl TE, Van Thiel DH. Complications of sclerotherapy for esophageal varices in liver transplant candidates. Transplant Proc 1990; 22 . 2149-51.

19 Iwatsuki S, Starzl TE, Todo S, et al. Lover transplantation in the treatment of bleeding esophageal varices. Surgery 1988; 104: 697-705.

20 Mazzaferro V, Todo S, Tzakis AG, Steiber AC, Makoka L, Starzl TE. Liver transplantation in patients with previous portasystemic shunt. Am $\mathcal{F}$ Surg 1990; 160: $111-6$

21 Sarfeh IJ, Rypins EB, Mason GR. A systemic appraisal of portacaval $\mathrm{H}$-shun diameters: clinical and hemodynamic perspectives. Ann Surg 1986; 204 356-63.

22 Villeneuve JP, Pomier-Layrargues G, Duguay L, et al. Emergency portacaval shunt for variceal hemorrhage. A prospective study. Ann Surg 1987; 206: 48-52.

23 Cello JP, Grendell JH, Crass RA, Wever TE, Trunkey DD. Endoscopic sclerotherapy versus portacaval shunt in patients with severe cirrhosis and sclerotherapy versus portacaval shunt in patients with severe

24 Spina GP, Santambrogio R, Opocher E, et al. Distal splenorenal shunt versus endoscopic sclerotherapy in the prevention of variceal rebleeding. First stage endoscopic sclerotherapy in the prevention of variceal rebleeding.
of a randomized, controlled trial. Ann Surg 1990; 211: 178-86.

25 Burroughs AK, Hamilton G, Phillips A, Mezzanotte G, McIntyre N, Hobbs KEF. A comparison of sclerotherapy with staple transection of the esophagus for the emergency control of bleeding from esophageal varices. $N$ Engl $\mathcal{F}$ Med 1989; 321: 857-62.

26 Hosking SW, Johnson AG. What happens to esophageal varices after transection and devascularisation. Surgery 1987; 101: $531-4$.

27 Millikan WJ, Henderson JM, Galloway JR, Dodson TF, Shires GT 3d, Stavard M. Surgical rescue for failures of cirrhotic sclerotherapy. Am f Surg 1990; 160: 117-21

28 Paquet KH. Open discussion on technical aspects of injection sclerotherapy. In: Westaby D, MacDougall BRD, Williams R, eds. Variceal bleeding. London: Pitman Press, 1982: 215-7.

29 Sarin SK, Sachdev G, Nanda R, Misra SP, Broor SL. Endoscopic sclerotherapy in the treatment of gastric varices. Br F Surg 1988; 75: 747-50. 
30 Terblanche J, Northover JM, Bornman PC, et al. A prospective evaluation of injection sclerotherapy in the treatment of acute bleeding from esophageal injection sclerotherapy in the tre

31 Clark AW, MacDougall BRD, Westaby D, et al. Prospective controlled trial of injection sclerotherapy in patients with cirrhosis and recent variceal haemorinjection sclerotherapy in patient

32 Mathur SK, Dalvi AN, Someshwar V, Supe AN, Ramakantan R. Endoscopic and radiological appraisal of gastric varices. Br f Surg 1990; 77: 432-5.

33 Sarin SK, Kumar A. Gastric varices: profile, classification and management. Am $\mathcal{F}$ Gastroenterol 1989; 84: 1244-9.

34 Lebrec D, Benhamou J-P. Ectopic varices in portal hypertension. Clin Gastroenterol 1985; 14: 105-21.

35 Khouqeer F, Morrow C, Jordan P. Duodenal varices as a case of massive upper gastrointestinal bleeding. Surgery 1987; 102: 548-52.

36 Rabinowitz M, Schade RR, Dindzans VJ, Belle SH, Van Thiel DH, Gavaler JS. Colonic disease in cirrhosis. An endoscopic evaluation in 412 patients. Gastroenterology 1990; 99: 195-9.

37 Hosking SW, Smart HL, Johnson AG, Triger DR. Anorectal varices, haemorrhoids and portal hypertension. Lancet 1989; i: 349-52.

38 Thomson WHF. The nature of haemorrhoids. Br F Surg 1975; 62: 542-52.

39 Weinshel E, Chen W, Falkenstein DB, Kessler R, Raicht RF. Haemorrhoids or rectal varices: defining the cause of massive rectal hemorrhage in patients or rectal varices: defining the cause of massive rectal hemorth

40 Hosking SW, Johnson AG. Bleeding anorectal varices - a misunderstood condition. Surgery 1988; 104: 70-3.

41 McCormack TT, Bailey HR, Simms JM, Johnson AG. Rectal varices are not piles. Br f Surg 1984; 71: 163

42 Smith S, Wiener ES, Starzl TE, Rowe MI. Stoma-related variceal bleeding: an under-recognized complication of biliary atresia. F Pediatr Surg 1988; 23: 243-5.

43 Fox L, Crane SA, Bidari C, Jones A. Intra-abdominal hemorrhage from ruptured varices. Arch Surg 1982; 117: 953-6.

44 Bloor K, Orr W. A case of haemorrhage from varices in the small intestine due to portal hypertension. BrF Surg 1961; 48: 423-4.

45 Fry RD, Fischer KC, Susman N, Shatz BA, Hulbert B. Adhesions-related variceal hemorrhage following sclerosis of esophageal varices. Arch Surg 1988; 123: 94-5.

46 Moncure AC, Waltman AC, Vandersalm TJ, Linton RR, Levine FH, Abbott WM. Gastrointestinal hemorrhage from adhesion-related mesenteric varices. Ann Surg 1976; 183: 24-9.

47 Reilly JJ, Schade RR, Van Thiel DS. Esophageal function after injection sclerotherapy: pathogenesis of esophageal stricture. Am F Surg 1984; 147: $85-8$.

48 Stringer MD, Howard ER, Mowat AP. Endoscopic sclerotherapy in the management of esophageal varices in 61 children with biliary atresia. f Pediatr Surg 1989; 24: 438-42.

49 Tahibian N, Schwartz JT, Smith JL, Graham DY. Cardiac tamponade as a result endoscopic sclerotherapy: report of a case. Surgery 1987; 102: 546-7.
50 Bacon DR, Bailey-Newton RS, Connors AF. Pleural effusions after endoscopic variceal sclerotherapy. Gastroenterology 1985; 88: 1910-4.

51 Gertsch P, Mossimann R. Chylothorax complicating sclerotherapy for bleeding oesophageal varices. Brf Surg 1983; 78: 562.

52 Carr-Lock DL, Sidhy K. Broncho-oesophageal fistula: a late complication of endoscopic variceal sclerotherapy. Gut 1982; 23: 1005-7.

53 Sorensen T, Bucharth F, Penderson ML, Findahl F. Oesophageal stricture and dysphagia after endoscopic sclerotherapy for bleeding varices. Gut 1984; 25 : $473-7$.

54 Stringer MS, Howard ER. The role of endoscopic injection sclerotherapy in the management of portal hypertension in children. In: Howard ER, ed. Surgery of liver disease in children. Oxford: Butterworth-Heinemann, 1991: 155-70.

55 Greenholz SK, Hall RJ, Sonheimer JM, Lilly JR, Hernandez-Cano AM. Manometric and $\mathrm{pH}$ consequences of esophageal endosclerosis in children. f Pediatr Surg 1988; 23: 38-41.

56 Chaudhary A, Tatke M, Aranya RC. Endoscopic sclerotherapy: the near and far effects. Br F Surg 1990; 77: 963.

57 Barsoum MS, Bolous FI, El-Rooby AA, Rizk-Allah MA, Ibrahim AS Tamponade and injection sclerotherapy in the management of oesophageal varices. BrF Surg 1982; 69: 76-8.

58 Stoltenberg PH, Goodale RL, Silvis SE. Portal vein thrombosis following combined endoscopic variceal sclerosis and vasopressin therapy for bleeding combined endoscopic variceal sclerosis and vas

59 Hunter GC, Steinkirchner T, Burbige EJ, Guernsey JM, Putnam CW. Venous complications of sclerotherapy for esophageal varices. Am F Surg 1988; 157: $497-50$

60 Snady H. Acute portal vein thrombosis, sclerotherapy and vasopressin: relationships and implications. Am $\mathcal{F}$ Gastroenterol 1987; 82: 1292.

61 Seidman E, Weber AM, Morin CL, et al. Spinal cord paralysis following sclerotherapy for esophageal varices. Hepatology 1984; 4: 950-4.

62 Cohen FL, Koerner RS, Taub SJ. Solitary brain abscess following endoscopic injection sclerosis of esophageal varices. Gastrointest Endosc 1985; 31: 331-3.

$63 \mathrm{Ng}$ WD, Chan YT. Digital gangrene complicating intraoperative injection sclerotherapy. Gastrointest Endosc 1988; 34: 151-3.

64 Yamaga H, Hashizume M, Kitano S, Higashi H, Yoshino I, Sugimachi K. Acute renal failure after endoscopic injection sclerotherapy: a report of two cases. Endoscopy 1989;21: 43 .

65 Tang H, Salem H, Wood L, Dudley F. Coagulopathy following endoscopic variceal sclerotherapy: comparison of two sclerosants. Gastrointest Endosc variceal scleroth

66 Bellary SV, Isaacs P. Disseminated intravascular coagulation (DIC) after endoscopic injection sclerotherapy with ethanolamine oleate. Endoscopy 1990; 22: 151

67 Sauerbruch T, Holl J, Ruckdeschel G, Forstl J, Weinzierl M. Bacteraemia associated with endoscopic sclerotherapy of esophageal varices. Endoscopy 1985; 17: 170-2.

68 Bordas JM, Feu F, Vitella A, Rodes J. Anaphylactic reaction to ethanolamine oleate injection in sclerotherapy of esophageal varices. Endoscopy 1989; 21 : 50 